\title{
A Coupled Discrete-Finite Element Method for Shear Strength Analysis of Geogrid-Reinforced Railway Ballast
}

\author{
Danyang Ji $\mathbb{D}^{D}$, Zheng Ma $\mathbb{D}^{D}$, Junjie Zhou $(\mathbb{D}$, Yajun Li $\mathbb{D}$, and Shuai Shao \\ Transportation Institute, Inner Mongolia University, Hohhot 010070, China \\ Correspondence should be addressed to Shuai Shao; shao870402@126.com
}

Received 8 November 2021; Revised 16 December 2021; Accepted 18 December 2021; Published 31 December 2021

Academic Editor: Bingxiang Yuan

Copyright (C) 2021 Danyang Ji et al. This is an open access article distributed under the Creative Commons Attribution License, which permits unrestricted use, distribution, and reproduction in any medium, provided the original work is properly cited.

\begin{abstract}
This paper presents a coupled discrete-finite element method for the investigation of shear strength of geogrid-reinforced ballast by direct shear tests and pull-out tests. The discrete element method (DEM) and finite element method (FEM) are employed to simulate ballast and geogrid, respectively. Irregularly shaped ballast particles are modeled with clumps, and the nonlinear contact force model is used to calculate contact force between particles. Continuum geogrid is modeled by a two-node beam element with six degrees of freedom. A contact algorithm based on the static equilibrium is proposed at the geogrid-ballast contact surface. The simulation results indicate that shear strengths increase with the installation of geogrid. Moreover, ballast particle displacements and nominal volumetric strains are analyzed to provide a microscopic view on the mechanism of the reinforcement effect of geogrid.
\end{abstract}

\section{Introduction}

In order to ensure the stability of geotechnical materials, appropriate reinforcement measures are very necessary [1]. As an economic and effective technique, geogrid reinforcement of railway ballast is an alternative way to minimize ballast deformation [2]. Geogrids can provide lateral and vertical confinement to ballast, thereby reducing its settlement and minimizing particle breakage [3]. Available literature has provided an insight into the performance of reinforced ballast $[4,5]$. These studies show that the rate of permanent deformation associated with lateral ballast spreading can be reduced effectively by the use of geogrid reinforcement. The reinforcement effect is generally attributed to the tensile strain generated by the interlocking action between geogrid and surrounding aggregate.

Laboratory test and numerical simulation are two important ways to study the mechanical behavior of geomaterials [6, 7]. In recent years, numerical methods have developed rapidly with the development of computer. As an effective numerical approach, the discrete element method has been used to analyze the geogrid-reinforced ballast behaviors $[8,9]$. Miao et al. [10] presented the pull-out behavior of a triangular geogrid embedded in ballast under special consideration of the particle size using the discrete element method. The results unveiled the optimal reinforcement scheme. Chen et al. [11] simulated the behaviors of geogrid-reinforced ballast under confined and unconfined conditions under cyclic loading. The responses of geogridreinforced ballast with different geogrid positions, geogrid apertures, and geogrid numbers were investigated. The finite element method (FEM) has been widely used in various fields through decades of development $[12,13]$. You et al. [14] evaluated the load-carrying capacity of a prestressed concrete sleeper using LS-DYNA. The results of this study lead to better insight into the influences of rail seat abrasion more clearly and improve track maintenance and inspection criteria.

The coupling method can give full play to the advantages of different numerical methods. In recent years, the coupling method has attracted more and more attention of researchers [15, 16]. Nishiura et al. [7] developed a quadruple discrete element method for viscoelastic multibody dynamics. The sleeper motion modeled using the quadruple discrete element method was coupled with the rail motion modeled using a finite element method. This study suggests 
that the proposed QDEM-FEM can provide greater insight into the impact response of ballasted railway tracks. Bai et al. [17] established a coupled thermo-hydro-mechanical mechanism in view of the soil particle rearrangement for saturated/unsaturated soils under the framework of granular thermodynamics. The established model spans the complete process from unsaturated to saturated soils and is verified by the typical test results.

The interaction between geogrid and ballast is an interaction of structure with granular media. The coupling of the finite element method (FEM) with the DEM is an effective approach for such problems [18-20]. The finite element method is used to model the continuum structure, and the discrete element method is used to model discrete particles. Researchers have conducted some useful studies on the coupled discrete-finite element method. Tran et al. [21] developed a coupled finite-discrete framework to investigate the behavior of a biaxial geogrid sheet embedded in granular soil and subjected to pull-out loading. The detailed responses of the geogrid and surrounding soil were investigated. The contact algorithm at the interface of structure and granular media is the key of the coupled discrete-finite method.

In this paper, a coupled discrete-finite element method is developed to analyze the shear strength of geogrid-reinforced ballast by direct shear tests and pull-out tests. The DEM and FEM are employed to simulate ballast and geogrid, respectively. A contact algorithm is proposed at the geogridballast contact surface. The reinforcement effect of geogrid is investigated by contrasting the results of direct shear tests and pull-out tests.

\section{The Numerical Model of Ballast and Geogrid}

2.1. Generation of Ballast Particle Shapes. The irregular particle shape has a significant impact on the macromechanical behavior of geotechnical materials [22-24]. In order to generate the irregular shape of ballast stone, an arbitrary convex polyhedron is firstly generated and its surfaces are extracted as the ballast particle surfaces. The size and shape of ballast are both considered during the polyhedron generation. The polyhedron is then filled with spherical particles with uniform particle size. In order to obtain a more accurate ballast particle shape, each particle will expand continuously. The system is finally stabilized by a cycling process until the sphere radius reaches its maximum and the location of each sphere does not change distinctly.

In consideration of the computational efficiency, one ballast stone contains several spheres. The real ballast stones and the generated clumps are shown in Figure 1. Each ballast particle consists of a number of overlapped spheres and behaves as a rigid body. The mass, center of mass, and moment of inertia of a clump in local coordinates are determined using the finite segment method [25]. The diameters of generated ballast particles range from $21 \mathrm{~mm}$ to $63 \mathrm{~mm}$ with the mean size of approximately $40 \mathrm{~mm}$. The ballast sizes and gradation used in the numerical simulations are shown in Figure 2.
2.2. Contact Force Model. The contacts between clumps are contacts of two regular spheres [26]. Based on Hertz's theory of the particle-particle contact of two elastic spheres, the normal contact force consists of elastic and viscous forces and can be written as [27]

$$
F_{n}=K_{n} x_{n}^{3 / 2}+\frac{3}{2} A K_{n} x_{n}^{3 / 2} \dot{x}_{n}
$$

Without considering the viscous force and considering the Mohr-Coulomb friction law, the tangential contact force can be determined as [28]

$$
\begin{aligned}
F_{s}^{*} & =K_{s} x_{n}^{1 / 2} x_{s}, \\
F_{s} & =\min \left(F_{s}^{*}, \operatorname{sign}\left(F_{s}^{*}\right) \mu F_{n}\right),
\end{aligned}
$$

where $x_{n}$ and $\dot{x}_{n}$ are the normal deformation and deformation rate, $x_{s}$ is the shear deformation, $K_{\mathrm{n}}$ and $K_{\mathrm{s}}$ are the normal contact stiffness and tangential contact stiffness, $\mu$ is the friction coefficient, and $A$ is a material constant depending on Young's modulus, viscous coefficients, and Poisson's ratio of the material and can be determined by the restitution coefficient of particle collisions at a certain speed. $K_{\mathrm{n}}$ and $K_{\mathrm{s}}$ can be calculated as

$$
\begin{aligned}
& K_{n}=\frac{4}{3} E^{*} \sqrt{R^{*}}, \\
& K_{s}=8 G^{*} \sqrt{R^{*}},
\end{aligned}
$$

where $E^{*}=E / 2\left(1-v^{2}\right), G^{*}=G / 2(2-v), G=E / 2(1+v)$, and $R^{*}=R_{A} R_{B} / R_{A}+R_{B} . E, v$, and $G$ are Young's modulus, Poisson's ratio, and shear modulus of the material, respectively. $R_{A}$ and $R_{B}$ are the radii of the two contiguous particles.

The maximum time step in the nonlinear DEM can be determined by

$$
t_{\max }=\frac{\pi R_{\min }}{0.163 v+0.8766} \sqrt{\frac{\rho}{G}} .
$$

The real time step in the calculation is less than the maximum and is determined by

$$
\Delta t=\alpha t_{\max }
$$

where $\alpha$ is an empirical coefficient. Normally, with higher coordination number $(>4), \alpha=0.2$, and with lower coordination number $(<4), \alpha=0.4$. In this study, we set $\alpha=0.2$.

2.3. Finite Element Model of Geogrid. Geogrid is a kind of typical geosynthetics with unique structural properties and is widely used in the reinforced soil $[29,30]$. In order to study the behavior of geogrid in ballast, the finite element method was used to simulate the dynamic character of geogrid. In this study, a geogrid with an aperture of $40 \mathrm{~mm} \times 40 \mathrm{~mm}$ is modeled by an elastic two-node beam element with circular section as shown in Figure 3. The radius of each element is $3 \mathrm{~mm}$. The finite element model of geogrid contains totally 54 elements and 45 nodes. The central difference method is employed to obtain the numerical solutions of the dynamic 


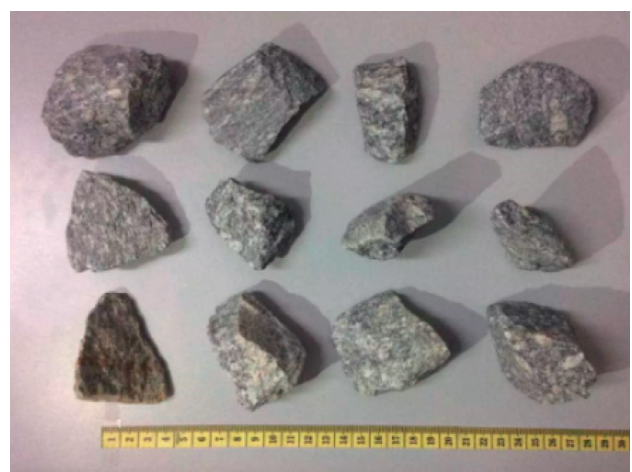

(a)

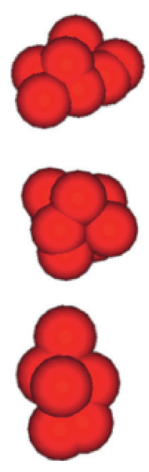

.

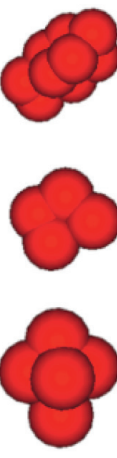

(b)

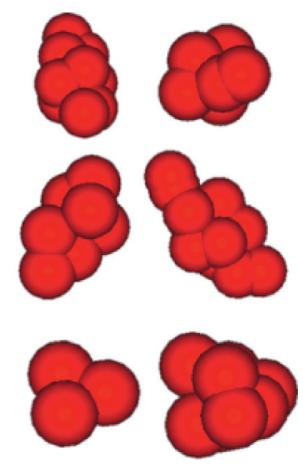

FIGURE 1: Ballast particles and constructed elements of ballast in DEM. (a) Real ballast. (b) DEM model of ballast particles.

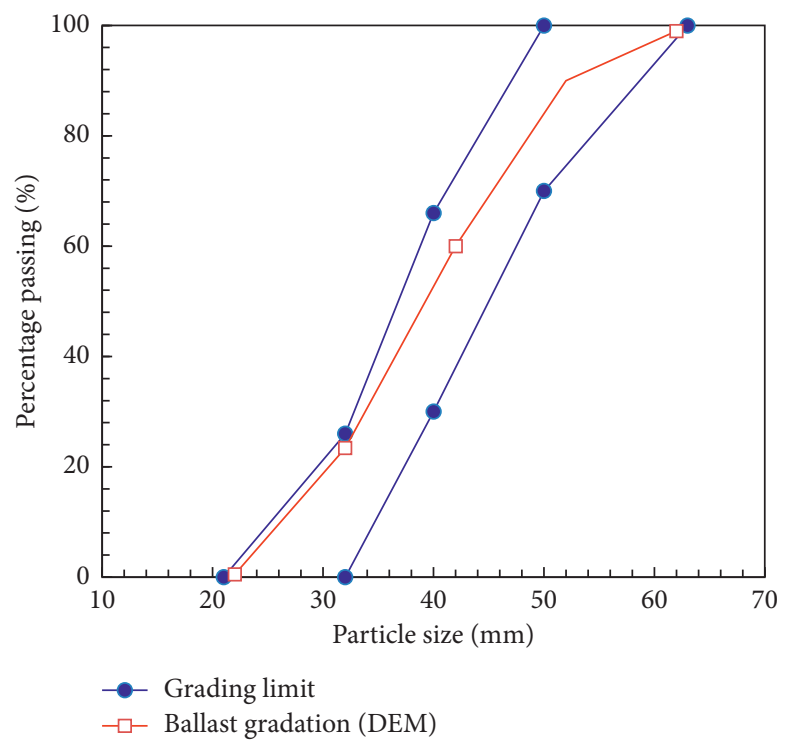

Figure 2: Particle sizes and gradation of ballast.

responses of the geogrid. The computational parameters are shown in Table 1.

\section{Coupling of Discrete and Finite Element Methods}

The transmissions of the mechanical variables at the interface between ballast and geogrid are important for the coupled DEM-FEM analysis of shear strength of geogrid-reinforced ballast. The contact forces obtained from the discrete element method are treated as the force boundary condition in the finite element method. The deformations of the geogrid are treated as the displacement boundary condition in the discrete element method. However, the contact forces calculated from the DEM do not always act on the nodes of the finite element. To solve the problem, a contact algorithm based on the static equilibrium is proposed to obtain the equivalent nodal loads of the finite element.
A coordinate system $x_{1} x_{2} x_{3}$ is established as shown in Figure 4 , and the equivalent nodal forces components at both ends can be calculated as

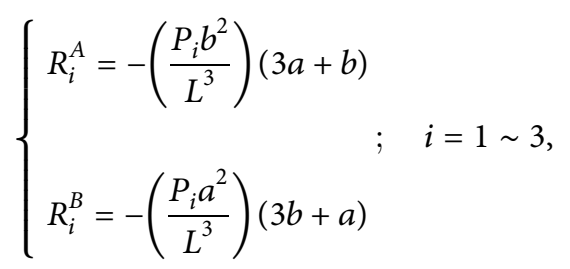

where $R_{A}$ and $R_{B}$ are the equivalent nodal forces on the beam element, $P$ is the external load obtained from the DEM, $L$ is the length of beam element, $a$ is the distance between contact point and end point $A$, and $b$ is the distance between contact point and end point $B$.

The time step of the finite element is based on the natural period $T$ of the geogrid vibration and can be calculated as 

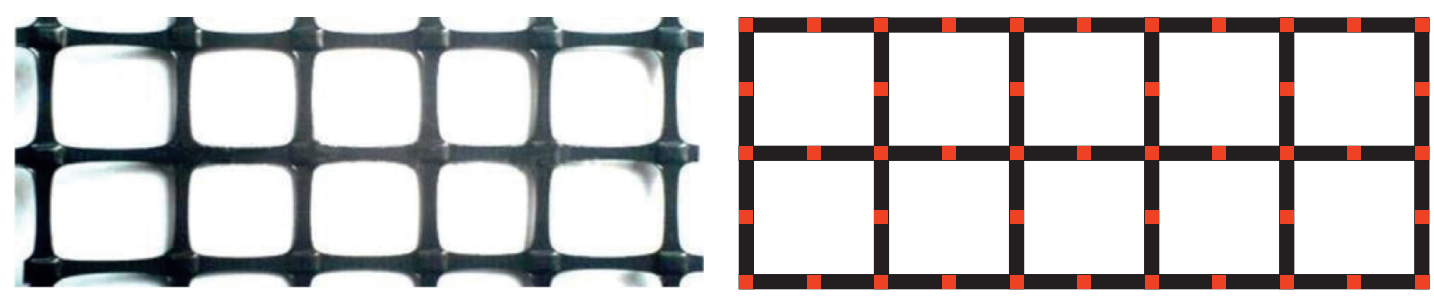

- Node

Element

(a)

(b)

FIGURE 3: The geogrid type and its FEM model. (a) Geogrid type. (b) FEM model of geogrid.

TABLE 1: Computational parameters of FEM.

\begin{tabular}{lc}
\hline Parameters & Values \\
\hline Cross section area of beam element & $2.83 \times 10^{-5} \mathrm{~m}^{2}$ \\
Inertia moment & $1.02 \times 10^{-9} \mathrm{~mm}^{4}$ \\
Rotational inertia & $2 \times 10^{-9} \mathrm{~kg} \mathrm{~m}^{2}$ \\
Elasticity modulus & $200 \mathrm{GPa}$ \\
Shear modulus & $80 \mathrm{GPa}$ \\
\hline
\end{tabular}

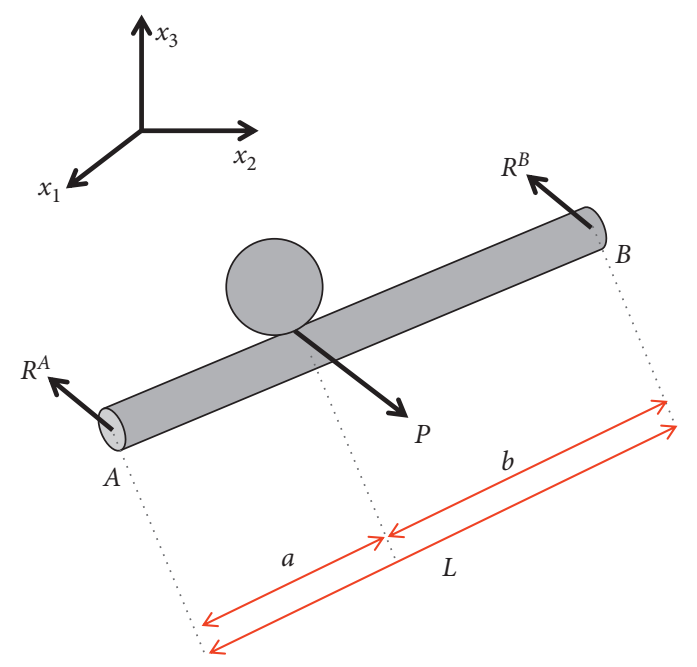

Figure 4: Schematic of contact algorithm between DEM and FEM.

$$
\Delta t \leq \frac{T}{20} .
$$

\section{Shear Strength Analysis of Geogrid- Reinforced Ballast}

4.1. Numerical Models of Direct Shear Test and Pull-Out Test. The DEM model of direct shear test of unreinforced ballast, the coupled DEM-FEM model of direct shear test of reinforced ballast, and the coupled DEM-FEM model of pull-out test are shown in Figure 5. The geogrid was inserted at the position of the shearing surface. The length, width, and height of the numerical specimen are $0.45 \mathrm{~m}, 0.23 \mathrm{~m}$, and $0.45 \mathrm{~m}$, respectively. Each model consisted of 747 clumps constructed with 4398 spheres. The initial porosity was approximately 0.44 . For each specimen, a normal stress in the range of $100-500 \mathrm{kPa}$ was applied on top of the shear box. At the same time, a constant shearing rate of $6.4 \mathrm{~mm} / \mathrm{s}$ was applied horizontally to the upper shear box in direct shear tests and to the left-hand end of the geogrid in pull-out tests. Main computational parameters of ballast are listed in Table 2.

4.2. Shear Stress-Displacement Analysis. The shear stresses against shear displacements of direct shear test without and with geogrid and pull-out test are shown in Figure 6. For all specimens, the strain-softening behaviors are observed, and the peak stress increases with the increase of normal stress. The reinforcement effect of geogrid is illustrated through the comparisons of simulation results of the three tests. The 
maximum shear stress under the normal stress of $100 \mathrm{kPa}$ rises from $178 \mathrm{kPa}$ in direct shear test without geogrid to $234 \mathrm{kPa}$ in direct shear test with geogrid and $567 \mathrm{kPa}$ in pullout test. Moreover, the slope of the shear stress-displacement curve rises under reinforced conditions. The slope under $500 \mathrm{kPa}$ rises from 13.3 in unreinforced specimen to 27.2 in reinforced specimens in direct shear test and 43.1 in pull-out test.

Due to the large particle size, the fluctuation of shear stress could be observed in Figure 6. The particles on the shear surface skip over the particles beneath during the shear process. The bearing skeleton changes with the dislocation between particles. Once the bearing skeleton changes, the shear stress decreases rapidly.

Researchers have conducted some useful studies on geogrid-reinforced ballast. Qian et al. [31] carried out the triaxial test of ballast material reinforced by triangular and square aperture geogrids. Miao et al. [10] carried out the pull-out test of geogrid-stabilized ballast based on the discrete element method. Chen et al. [11] proposed a discrete element model for cyclic loads of geogrid-reinforced ballast under confined and unconfined conditions. These studies studied the reinforcement effect of geogrid on ballast materials. In this paper, the reinforcement effect of geogrid is further studied by comparing the direct shear test and pullout test results of ballast materials.

4.3. Ballast Particles' Displacements. In order to gain insight into the interlock effect between ballast particles and geogrid, ballast particles' displacement vectors are investigated as shown in Figure 7 for all the three tests under the normal stress of $500 \mathrm{kPa}$. In the direct shear test without geogrid, upper ballast particles move rightwards along with the upper shear box. Ballast particles along the shearing surface move rightwards obviously due to the friction between ballast particles. Rotation movements are presented during the shear process, especially for those particles below the shearing surface.

In direct shear test with geogrid, ballast particles in the upper shear box have a similar behavior to those in direct shear test without geogrid. However, ballast particles along the shearing surface no longer move along with the upper box due to the constraint of geogrid. The movements of ballast particles in the lower box show more stability under the protection of geogrid. The stability of ballast particles is enhanced obviously with the installation of geogrid.

In the pull-out test, ballast particles on the shearing surface produce large displacements following the movements of geogrid. The ballast particles above and beneath the shear surface move up and down due to the drive of particles on the shear surface. The relative motion between particles is not obvious.

4.4. Nominal Volumetric Strain. In order to reveal the mechanism of ballast-geogrid interlock, the nominal volumetric strain is employed to investigate the relative position changes of the clumps. Figure 8 shows the relative position changes of two adjacent clumps. $X_{i}$ and $x_{i}$ are global and local coordinate system, respectively. $X_{A}^{n}$ and $X_{B}^{n}$ and $X_{A}^{n+1}$ and $X_{B}^{n+1}$ are the centroid coordinates of clumps $A$ and $B$ at time steps $t_{n}$ and $t_{n+1}$ in the global coordinate system. $x_{A}^{n}$ and $x_{B}^{n}$ and $x_{A}^{n+1}$ and $x_{B}^{n+1}$ are the centroid coordinates of clumps $A$ and $B$ at time steps $t_{n}$ and $t_{n+1}$ in the local system. Accordingly, the distance between clumps $A$ and $B$ in global and local systems can be determined as

$$
\begin{aligned}
\Delta X_{B A}^{n} & =X_{B}^{n}-X_{A}^{n}, \\
\Delta X_{B A}^{n+1} & =X_{B}^{n+1}-X_{A}^{n+1}, \\
\Delta x_{B A}^{n} & =x_{B}^{n}-x_{A}^{n}, \\
\Delta x_{B A}^{n+1} & =x_{B}^{n+1}-x_{A}^{n+1} .
\end{aligned}
$$

The relationship between the global and local coordinates is written as

$$
\begin{aligned}
\Delta x_{B A}^{n} & =T_{1} \Delta X_{B A}^{n}, \\
\Delta x_{B A}^{n+1} & =T_{2} \Delta X_{B A}^{n+1},
\end{aligned}
$$

where

$$
\begin{aligned}
& T_{1}=\left|\begin{array}{cc}
\cos \alpha_{1} & \sin \alpha_{1} \\
-\sin \alpha_{1} & \cos \alpha_{1}
\end{array}\right|, \\
& T_{2}=\left|\begin{array}{cc}
\cos \alpha_{2} & \sin \alpha_{2} \\
-\sin \alpha_{2} & \cos \alpha_{2}
\end{array}\right|,
\end{aligned}
$$

where $\alpha_{1}$ and $\alpha_{2}$ are the angles of $X_{i}$ and $x_{i}$ at time steps $t_{n}$ and $t_{n+1}$.

The deformation gradient of the relative position of clumps $A$ and $B$ is defined in local system as

$$
\begin{aligned}
f_{n} & =\frac{\Delta x_{B A}^{n+1}}{\Delta x_{B A}^{n}} \\
& =R_{n} U_{n},
\end{aligned}
$$

where

$$
\begin{aligned}
R_{n} & =\left|\begin{array}{cc}
\cos \left(\alpha_{2}-\alpha_{1}\right) & -\sin \left(\alpha_{2}-\alpha_{1}\right) \\
\sin \left(\alpha_{2}-\alpha_{1}\right) & \cos \left(\alpha_{2}-\alpha_{1}\right)
\end{array}\right|, \\
U_{n} & =\left|\begin{array}{cc}
\lambda_{A B} & 0 \\
0 & 1
\end{array}\right|, \\
l_{A B} & =\Delta x_{B A}^{n}, \\
l_{A^{\prime} B^{\prime}} & =\Delta x_{B A}^{n+1}, \\
\lambda_{A B} & =\frac{l_{A^{\prime} B^{\prime}}}{l_{A B}}
\end{aligned}
$$

where $l_{A B}$ and $l_{A^{\prime} B^{\prime}}$ are the modules of $\Delta x_{B A}^{n}$ and $\Delta x_{B A}^{n+1}$. 


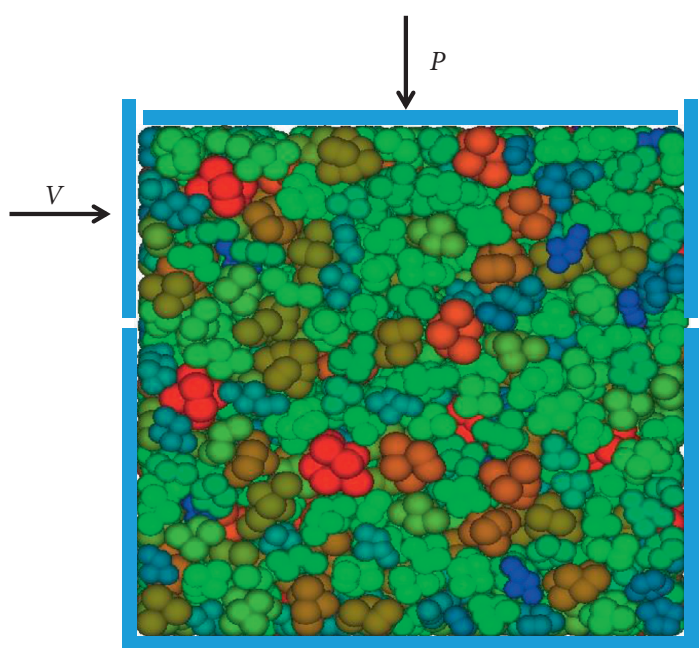

(a)

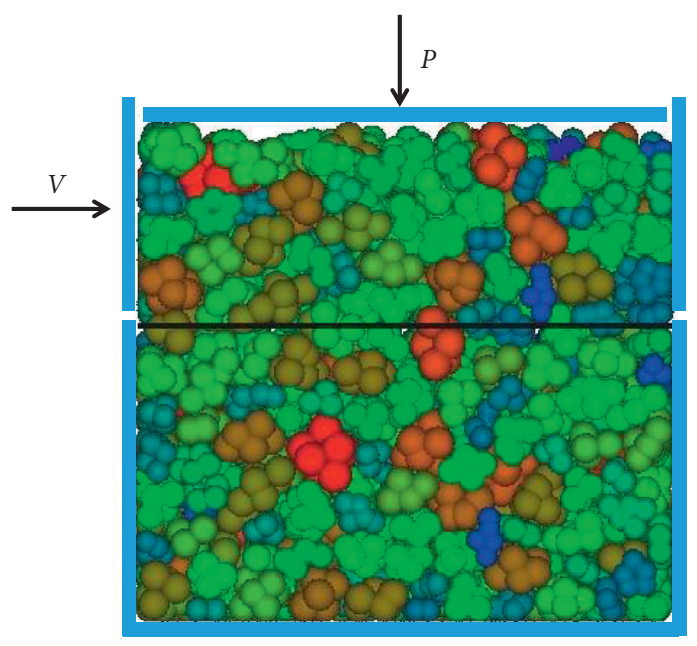

(b)

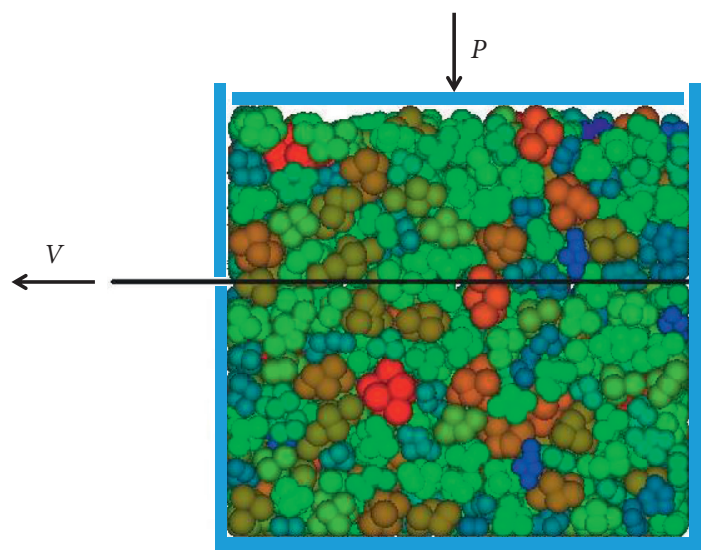

(c)

FIGURE 5: Numerical models of direct shear test without and with geogrid and pull-out test. (a) DEM model of direct shear test of unreinforced ballast. (b) Coupled DEM-FEM model of direct shear test of reinforced ballast. (c) Coupled DEM-FEM model of pull-out test.

TABLE 2: Computational parameters of DEM.

\begin{tabular}{lc}
\hline Parameters & Values \\
\hline Density of clump & $2545 \mathrm{~kg} / \mathrm{m}^{3}$ \\
Friction coefficient & $0.3-0.9$ \\
Normal stiffness & $3 \times 10^{7} \mathrm{~N} / \mathrm{m}$ \\
Shear stiffness & $2.6 \times 10^{6} \mathrm{~N} / \mathrm{m}$ \\
Young's modulus & $5 \times 10^{9} \mathrm{~Pa}$ \\
Poisson's ratio & 0.22 \\
\hline
\end{tabular}

Substitute (9) into (11):

$$
\begin{aligned}
\Delta X_{B A}^{n+1} & =F \Delta X_{B A}^{n}, \\
F & =T_{1}^{T} f_{n} T_{2} .
\end{aligned}
$$

The matrix of displacement derivatives can be written as

$$
D=F-I \text {, }
$$

where $I$ is the unit matrix.

We define the strain of clump A and clump B as

$$
V_{A B}=\left[\frac{2}{3} D_{i j} D_{i j}\right]^{1 / 2}
$$

Suppose clump $A$ had $N$ neighbors, and the strain of clump $A$ is defined as

$$
V_{A}=\frac{1}{N} \sum_{B=1}^{N} V_{A B} .
$$

The nominal volumetric strain is thus calculated as 

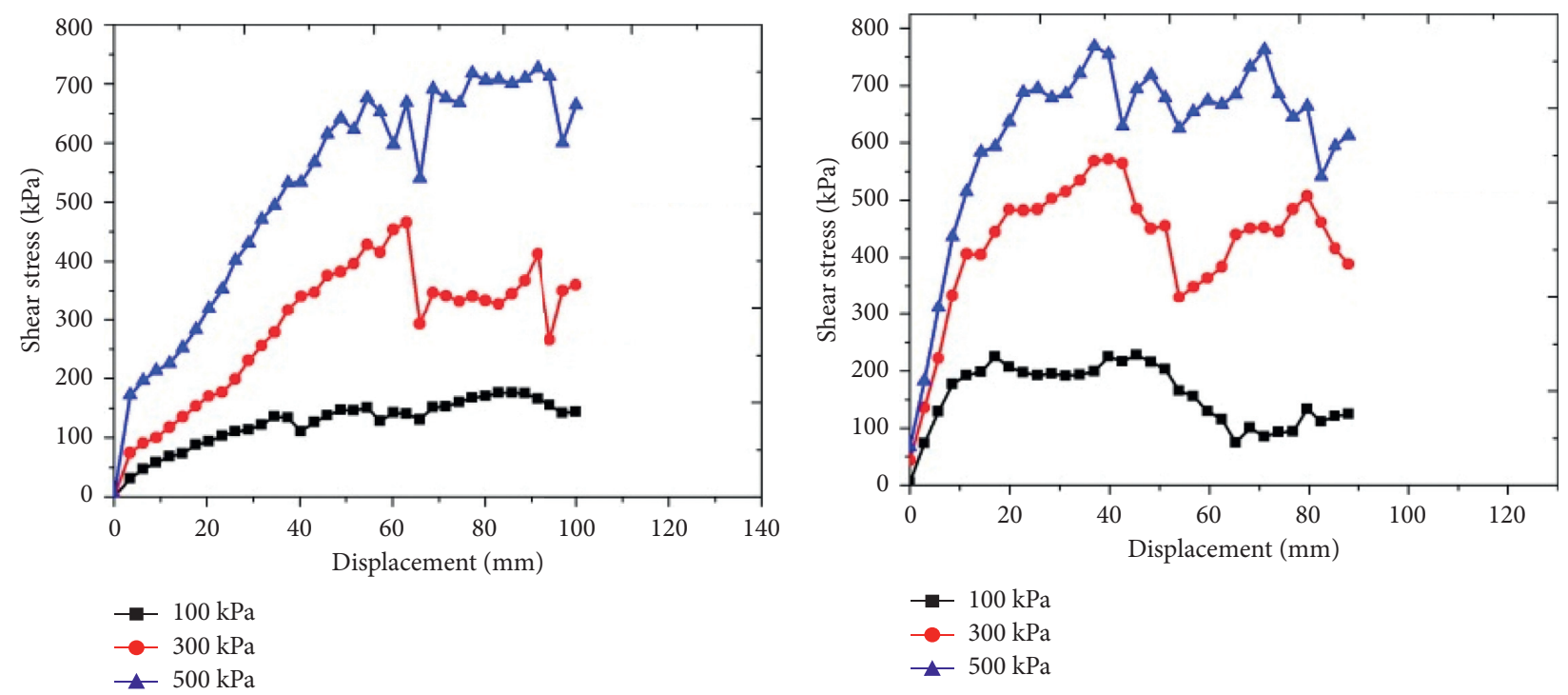

(a)

(b)

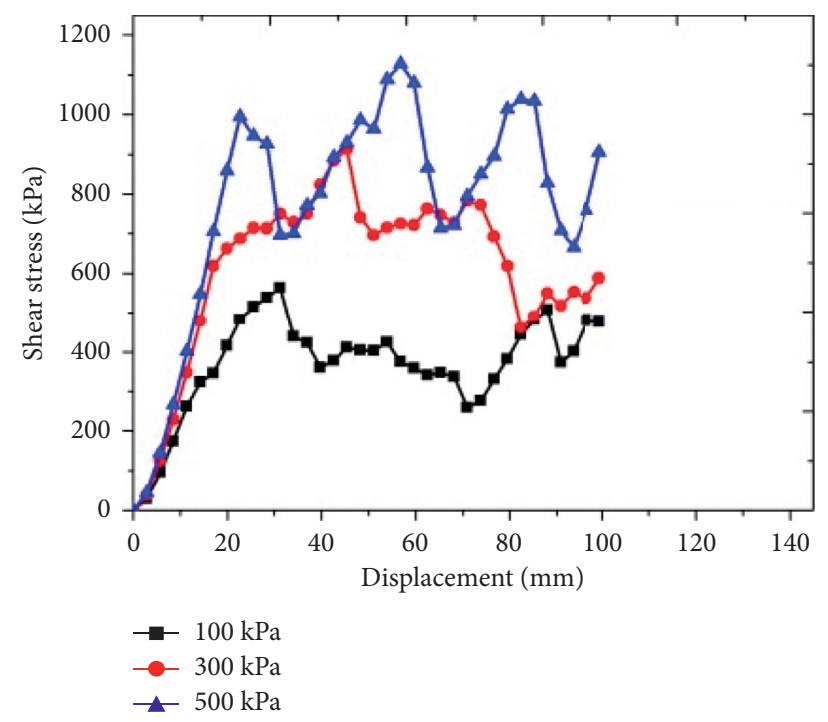

(c)

Figure 6: The shear stress-displacement curves of three different tests. (a) Direct shear test of unreinforced specimen. (b) Direct shear test of reinforced specimen. (c) Pull-out test.

$$
\begin{aligned}
& V_{A}^{V}=\frac{1}{N} \sum_{B=1}^{N} V_{A B}^{V}, \\
& V_{A B}^{V}=\lambda_{A B}-1 .
\end{aligned}
$$

The nominal volumetric strain of ballast particles is shown in Figure 9. For direct shear tests, simulation results are quite different between reinforced and unreinforced cases. In unreinforced specimen, large strains concentrate on both ends of the shearing surface, and only several dislocations occur in the inner part along the shearing surface. In contrast, in the reinforced specimen, the strain distribution is mainly located above the geogrid, and an obvious shear band can be observed. The dislocation of ballast particles is not obvious during the shearing process under the unreinforced case, and the nominal volumetric strain of ballast particles on the shearing surface is not obvious. The installation of geogrid provides horizontal and lateral constraints to ballast particles along shearing surface, which results in an obvious slide of particles and shear band in the upper box. The geogrid is helpful for the stability of particles in the lower box. In the pull-out test specimen, large strain distributes along both sides of the shearing surface due to the movement of geogrid.

The nominal volumetric strain of particles given in this part is only used to show the deformation of granular materials. In the discrete particle model, the description of particle properties is reflected by the force-displacement model at the contact point. The physical properties of a single particle are meaningful only at the mesolevel. The physical properties of granular materials composed of a 


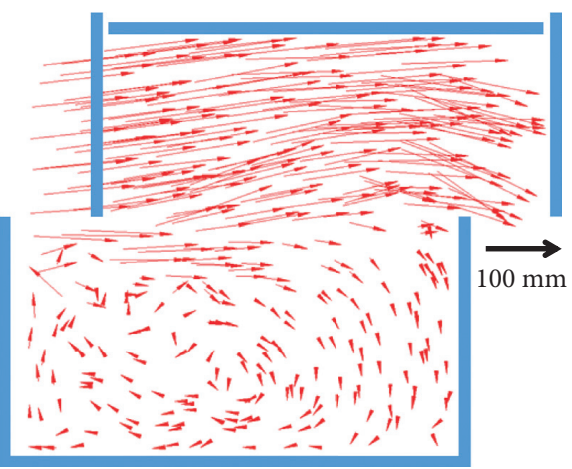

(a)

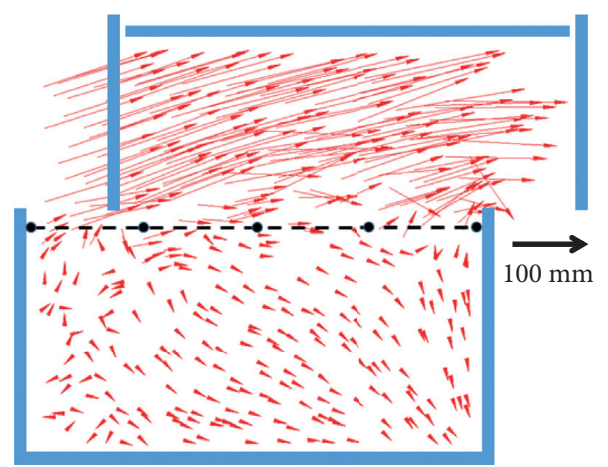

(b)

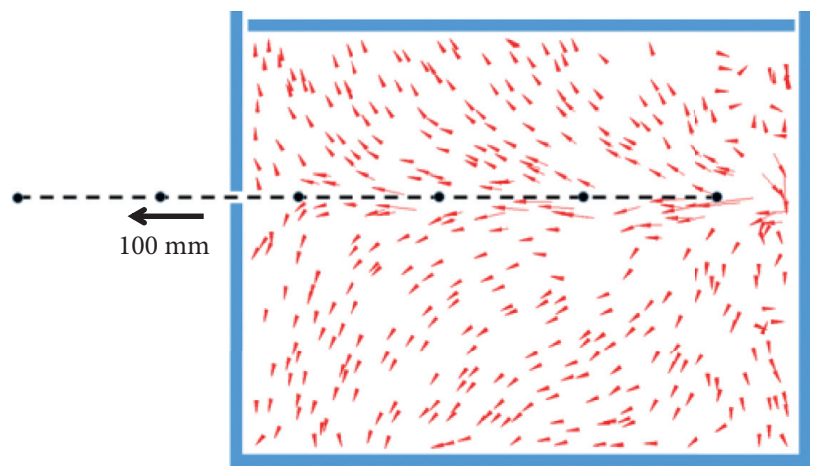

(c)

Figure 7: Particle displacements. (a) Direct shear of unreinforced specimen. (b) Direct shear of reinforced specimen. (c) Pull-out test.

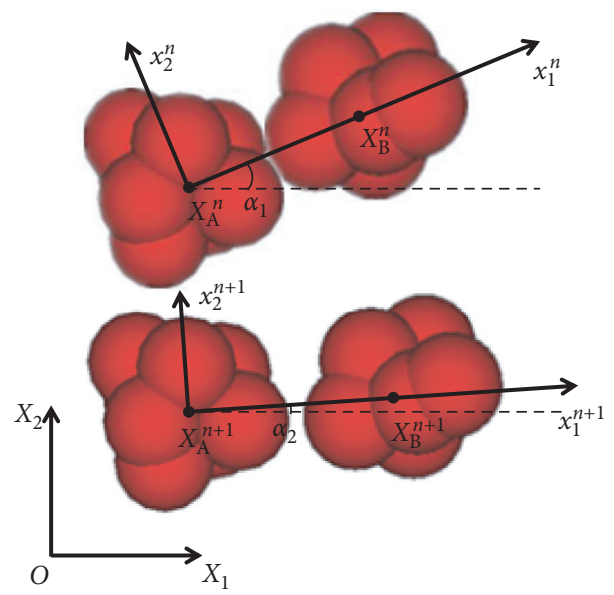

FIgURE 8: The relative position of clump (a) and neighboring clump (b).

large number of particles need to be described by constitutive relationship, which is related to the physical properties and arrangement of single particles. However, this paper focuses on using the discrete particle model to directly simulate the deformation of granular materials and does not discuss how to establish the nominal constitutive relationship of granular materials in the sense of continuum model. 


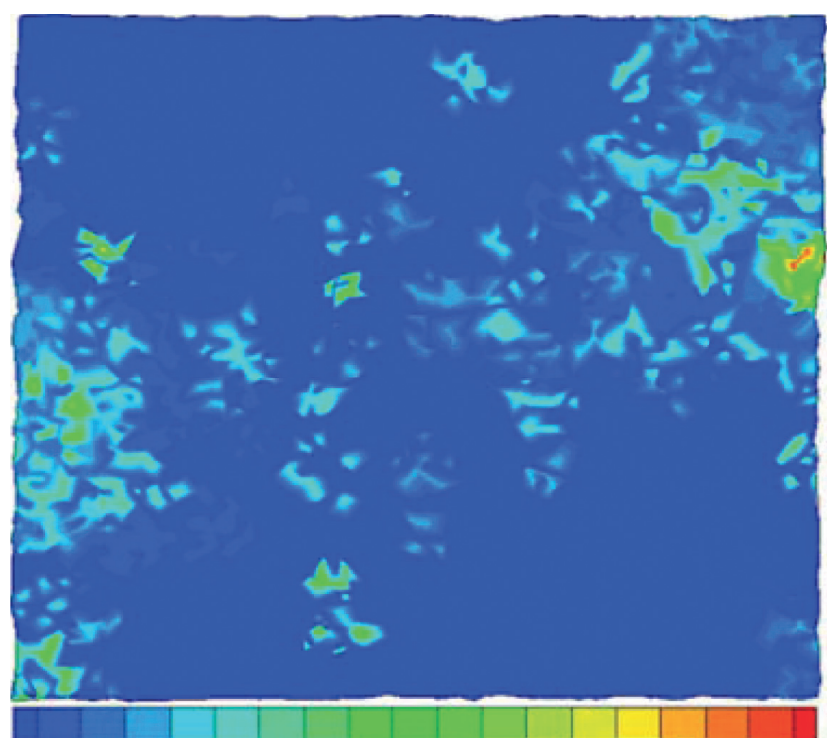

$\begin{array}{llllllllllllllllll}0.1 & 0.2 & 0.3 & 0.4 & 0.5 & 0.6 & 0.7 & 0.8 & 0.9 & 1 & 1.1 & 1.2 & 1.3 & 1.4 & 1.5 & 1.6 & 1.7 & 1.8\end{array}$

(a)

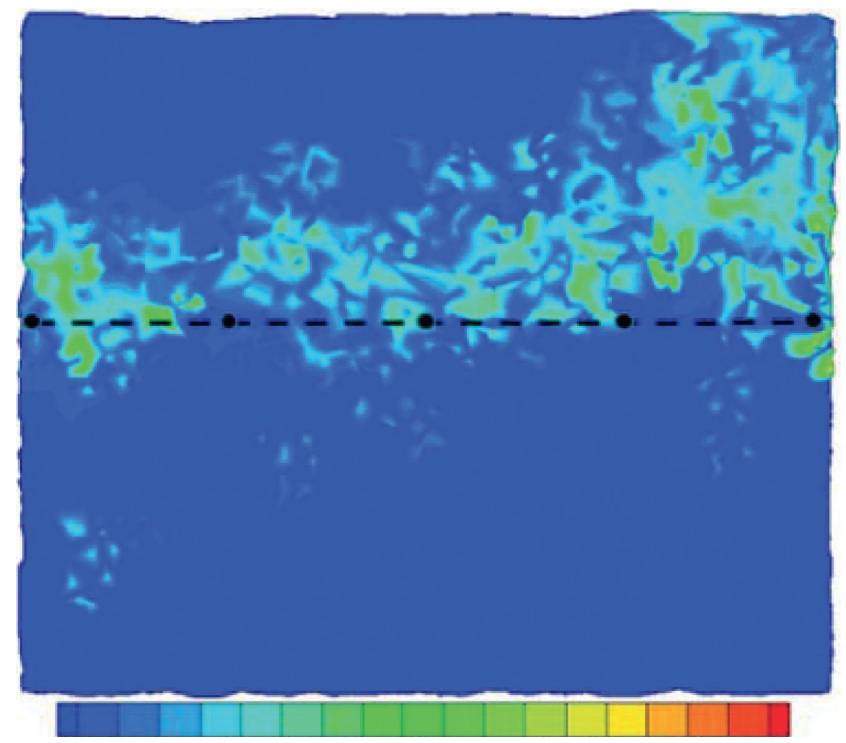

$0.10 .20 .30 .40 .50 .60 .70 .80 .9 \quad 1 \quad 1.11 .21 .31 .41 .51 .61 .71 .8$

(b)

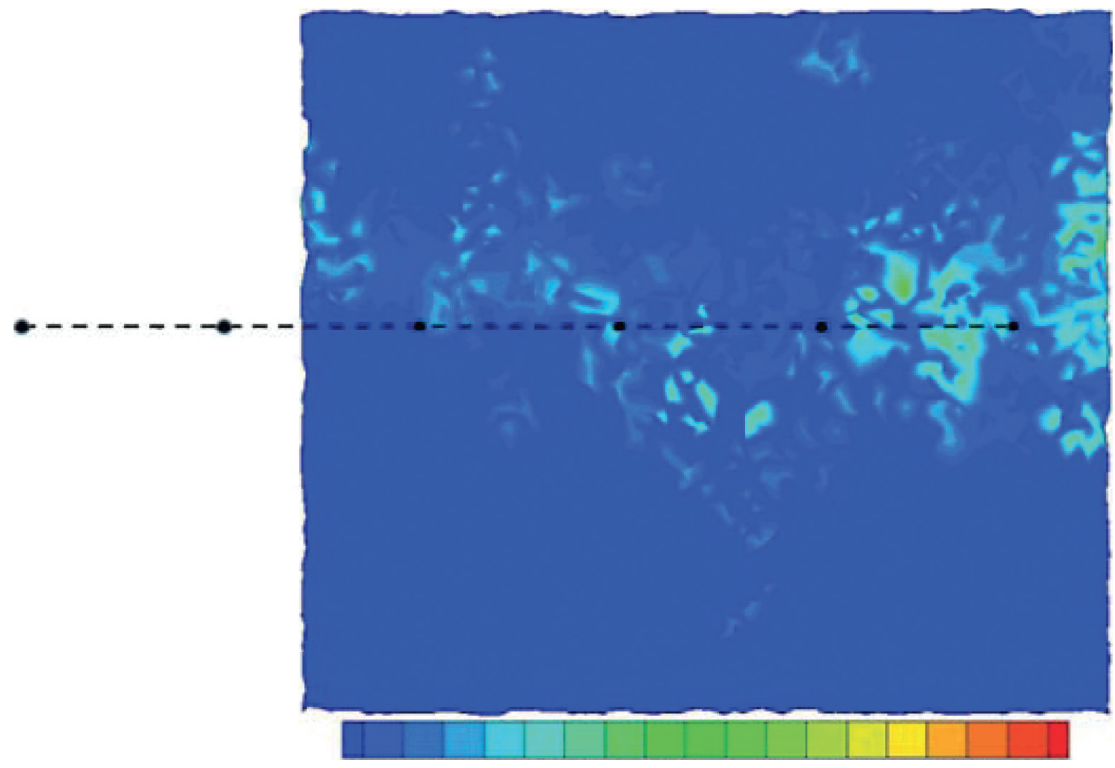

$0.10 .20 .30 .40 .50 .60 .70 .80 .9 \quad 1 \quad 1.11 .21 .31 .4 \quad 1.51 .61 .71 .8$

(c)

Figure 9: Nominal volumetric strain. (a) Direct shear test of unreinforced specimen. (b) Direct shear test of reinforced specimen. (c) Pullout test.

\section{Conclusions}

Shear strength of geogrid-reinforced ballast is modeled by a coupled discrete-finite element method through direct shear tests and pull-out tests. The discrete element and finite element are employed to model ballast and geogrid, respectively. A contact algorithm based on the static equilibrium is proposed at the geogrid-ballast contact surface. The behaviors of the geogrid-reinforced ballast are simulated and compared with those without geogrid.

The responses of the reinforced ballast are investigated by ballast particle displacements and nominal volumetric strains under microscale. The installation of geogrid provides horizontal and lateral constraints to ballast particles along shearing surface, and ballast particles along the shearing surface no longer move along with the upper box in the direct shear test. The strain distribution is mainly located above the geogrid, and obvious shear is formed. Geogrid can improve the stability of ballast materials.

The coupled discrete-finite element model proposed in this paper could reveal the mechanism of interaction between geogrid and ballast under microscale. It provides a new numerical method for dealing with similar problems. The mechanical behavior of geogrid is simulated by the 
elastic constitutive model, which is not very precise. The modeled shear test and pull-out test of reinforced ballast are still far away from modeling the practical functions of geogrid-reinforced ballast in engineering practice. In further work, the nonlinear constitutive model will be considered to analyze the behavior of geogrid.

\section{Data Availability}

The underlying data supporting the results of this study are uploaded as supplemental files.

\section{Conflicts of Interest}

The authors declare that they have no conflicts of interest.

\section{Acknowledgments}

This study was supported by the National Natural Science Foundation of China (no. 11802146), the Science and Technology Project of Inner Mongolia (no. 2020GG0126), and the Science and Technology Major Project of Inner Mongolia (no. 2020ZD0020).

\section{Supplementary Materials}

This section includes the data regarding the ballast direct shear test, geogrid direct shear test, and pull-out test. (Supplementary Materials)

\section{References}

[1] B. Yuan, Z. Li, Y. Chen et al., "Mechanical and microstructural properties of recycling granite residual soil reinforced with glass fiber and liquid-modified polyvinyl alcohol polymer," Chemosphere, vol. 268, Article ID 131652, 2021.

[2] B. Indraratna, T. Ngo, B. F. Ferreira, C. Rujikiatkamjorn, and A. Shahkolahi, "Laboratory examination of ballast deformation and degradation under impact loads with synthetic inclusions," Transportation Geotechnics, vol. 25, pp. 1-17, 2020.

[3] K. Sweta and S. K. K. Hussaini, "Effect of geogrid on deformation response and resilient modulus of railroad ballast under cyclic loading," Construction and Building Materials, vol. 264, pp. 1-13, 2020.

[4] S. K. K. Hussaini, B. Indraratna, and J. S. Vinod, "Performance assessment of geogrid-reinforced railroad ballast during cyclic loading," Transportation Geotechnics, vol. 2, pp. 99-107, 2015.

[5] J. Sadeghi, A. R. T. Kian, H. Ghiasinejad, M. F. Moqaddam, and S. Motevalli, "Effectiveness of geogrid reinforcement in improvement of mechanical behavior of sand-contaminated ballast," Geotextiles and Geomembranes, vol. 48, no. 6, pp. 768-779, 2020.

[6] B. Yuan, Z. Li, H. Ni, Z. Zhao, Z. Su, and Z. Li, "Experimental study of displacement field of layered soils surrounding laterally loaded pile based on Transparent Soil," Journal of Soils and Sediments, vol. 21, pp. 3072-3083, 2021.

[7] D. Nishiura, H. Sakai, A. Aikawa, S. Tsuzuki, and H. Sakaguchi, "Novel discrete element modeling coupled with finite element method for investigating ballasted railway track dynamics," Computers and Geotechnics, vol. 96, pp. 40-54, 2018.

[8] Z. Wang, F. Jacobs, M. Ziegler, and G. Yang, "Visualisation and quantification of geogrid reinforcing effects under strip footing loads using discrete element method," Geotextiles and Geomembranes, vol. 48, no. 1, pp. 62-70, 2020.

[9] G. Gao and M. A. Meguid, "Effect of particle shape on the response of geogrid-reinforced systems: insights from 3D discrete element analysis," Geotextiles and Geomembranes, vol. 46, no. 6, pp. 685-698, 2018.

[10] C. Miao, Y. Jia, J. Zhang, and J. Zhao, "DEM simulation of the pullout behavior of geogrid-stabilized ballast with the optimization of the coordination between aperture size and particle diameter," Construction and Building Materials, vol. 255, pp. 1-12, 2020.

[11] C. Chen, G. R. McDowell, and N. H. Thom, "Discrete element modelling of cyclic loads of geogrid-reinforced ballast under confined and unconfined conditions," Geotextiles and Geomembranes, vol. 35, pp. 76-86, 2012.

[12] T. H. M. Le, T. Lee, J. Seo, and D. Park, "Experimental investigation and numerical analysis on the performance of flowable soil as feasible backfill material for railway bridge approach," Transportation Geotechnics, vol. 28, Article ID 110542, 2021.

[13] B. Yuan, Z. Li, Z. Su, and Q. Luo, "Sensitivity of multistage fill slope based on finite element model," Advances in Civil Engineering, vol. 2021, Article ID 6622936, 2021.

[14] R. You, K. Goto, C. Ngamkhanong, and S. Kaewunruen, "Noninear finite element analysis for structural capacity of railway prestressed concrete sleepers with rail seat abrasion," Engineering Failure Analysis, vol. 95, pp. 47-65, 2019.

[15] S. Shao, Y. Yan, and S. Ji, "Combined discrete-finite element modeling of ballasted railway track under cyclic loading," International Journal of Computational Mehtods, vol. 14, no. 2, Article ID 1750047, 2017.

[16] B. Bai, D. Rao, T. Xu, and P. Chen, "SPH-FDM boundary for the analysis of thermal process in homogeneous media with a discontinuous interface," International Journal of Heat and Mass Transfer, vol. 117, pp. 517-526, 2018.

[17] B. Bai, R. Zhou, G. Cai, W. Hu, and G. Yang, "Coupled thermo-hydro-mechanical mechanism in view of the soil particle rearrangement of granular thermodynamics," Computers and Geotechnics, vol. 137, Article ID 104272, 2021.

[18] P. Villard, B. Chevalier, B. L. Hello, and G. Combe, "Coupling between finite and discrete element methods for the modelling of earth structures reinforced by geosynthetic," Computers and Geotechnics, vol. 36, no. 5, pp. 709-717, 2009.

[19] L. Guo, J. Xiang, J.-P. Latham, and B. Izzuddin, “A numerical investigation of mesh sensitivity for a new three-dimensional fracture model within the combined finite-discrete element method," Engineering Fracture Mechanics, vol. 151, pp. 70-91, 2016.

[20] B. Indraratna, N. T. Ngo, C. Rujikiatkamjorn, and S. W. Sloan, "Coupled discrete element-finite difference method for analysing the load-deformation behaviour of a single stone column in soft soil," Computers and Geotechnics, vol. 63, pp. 267-278, 2015.

[21] V. D. H. Tran, M. A. Meguid, and L. E. Chouinard, "A finitediscrete element framework for the 3D modeling of geogridsoil interaction under pullout loading conditions," Geotextiles and Geomembranes, vol. 37, pp. 1-9, 2013.

[22] H. Xiao, Z. Zhang, Y. Chi, M. Wang, and H. Wang, "Experimental study and discrete element analysis on dynamic mechanical behaviour of railway ballast bed in windblown sand areas," Construction and Building Materials, vol. 304, Article ID 124669, 2021.

[23] G. Jing, X. Zhang, and W. Jia, "Lateral resistance of polyurethane-reinforced ballast with the application of new 
bonding schemes: laboratory tests and discrete element simulations," Construction and Building Materials, vol. 221, pp. 627-636, 2019.

[24] Y. Wu, J. Cui, J. Huang, and W. Zhang, "Correlation of critical state strength properties with particle shape and surface fractal dimension of clinker ash," International Journal of Geomechanics, vol. 21, no. 6, Article ID 04021071, 2021.

[25] Y. Yan and S. Ji, "Discrete element modeling of direct shear tests for a granular material," International Journal for $\mathrm{Nu}$ merical and Analytical Methods in Geomechanics, vol. 34, no. 9, pp. 978-990, 2009.

[26] A. Danesh, A. A. Mirghasemi, and M. Palassi, "Evaluation of particle shape on direct shear mechanical behavior of ballast assembly using discrete element method (DEM)," Transportation Geotechnics, vol. 23, Article ID 100357, 2020.

[27] R. Ramírez, T. Pöschel, N. V. Brilliantov, and T. Schwager, "Coefficient of restitution of colliding viscoelastic spheres," Physical Review. E, Statistical Physics, Plasmas, Fluids, and Related Interdisciplinary Topics, vol. 60 , no. 4 Pt B, pp. 4465-4472, 1999.

[28] A. D. Renzo and F. P. D. Maio, "An improved integral nonlinear model for the contact of particles in distinct element simulations," Chemical Engineering Science, vol. 60, no. 5, pp. 1303-1312, 2005.

[29] C. Jayalath, C. Gallage, K. Wimalasena, J. Lee, and J. Ramanujam, "Performance of composite geogrid reinforced unpaved pavements under cyclic loading," Construction and Building Materials, vol. 304, Article ID 124570, 2021.

[30] R. Baadiga, S. Saride, U. Balunaini, and M. R. Madhira, "Influence of tensile strength of geogrid and subgrade modulus on layer coefficients of granular bases," Transportation Geotechnics, vol. 29, Article ID 100557, 2021.

[31] Y. Qian, D. Mishra, E. Tutumluer, and H. A. Kazmee, "Characterization of geogrid reinforced ballast behavior at different levels of degradation through triaxial shear strength test and discrete element modeling," Geotextiles and Geomembranes, vol. 43, no. 5, pp. 393-402, 2015. 